\section{BRAZIULIAN JOURNAL}

OF MEDICAL AND BIOLOGICAL RESHARCH

www.bjournal.com.br
ISSN 0100-879X

Volume 42 (8) 692-775 August 2009

CLINICAL INVESTIGATION

Braz J Med Biol Res, August 2009, Volume 42(8) 731-737

Variable positive end-expiratory pressure can maintain oxygenation in experimental acute respiratory distress syndrome induced by oleic acid in dogs

F.C. Lanza, M.C.P. Damasceno, F. Leme, A.C.Z. Yagui, K.C. Paiva, A. Luque and O.S. Beppu

The Brazilian Journal of Medical and Biological Research is partially financed by
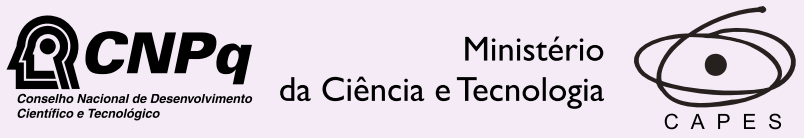

Ministério da Educação

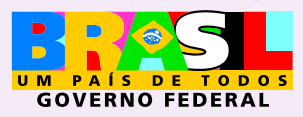

Institutional Sponsors 


\title{
Variable positive end-expiratory pressure can maintain oxygenation in experimental acute respiratory distress syndrome induced by oleic acid in dogs
}

\author{
F.C. Lanza ${ }^{1,2}$, M.C.P. Damasceno1 ${ }^{1}$, F. Leme ${ }^{1}$, A.C.Z. Yagui ${ }^{1}$, K.C. Paiva1, \\ A. Luque ${ }^{2,3}$ and O.S. Beppu ${ }^{1}$ \\ 1'Disciplina de Pneumologia, Departamento de Medicina, Escola Paulista de Medicina, \\ Universidade Federal de São Paulo, São Paulo, SP, Brasil \\ ${ }^{2}$ Centro Universitário São Camilo, São Paulo, SP, Brasil \\ ${ }^{3}$ Departamento de Medicina, Laboratório de Investigação Médica (LIM 12), \\ Faculdade de Medicina, Universidade de São Paulo, São Paulo, SP, Brasil
}

\begin{abstract}
The use of positive end-expiratory pressure (PEEP) or lung recruitment maneuvers (RM) to improve oxygenation in acute respiratory distress syndrome (ARDS) is used but it may reduce cardiac output (CO). Intermittent PEEP may avoid these complications. Our objective was to determine if variable PEEP compared with constant PEEP is capable of maintaining arterial oxygenation and minimizing hemodynamic alterations with or without RM. Eighteen dogs with ARDS induced by oleic acid were randomized into three equal groups: group 1, low variable PEEP; group 2, high variable PEEP, and group 3, RM + high variable PEEP. All groups were submitted to constant PEEP, followed by variable PEEP (PEEP was increased from 5 to $10 \mathrm{cmH}_{2} \mathrm{O}$ in group 1, and from 5 to $18 \mathrm{cmH}_{2} \mathrm{O}$ in the other two groups). $\mathrm{PaO}_{2}$ was higher in group 3 (356.2 $\left.\pm 65.4 \mathrm{mmHg}\right)$ than in group 1 $(92.7 \pm 29.7 \mathrm{mmHg})$ and group $2(228.5 \pm 72.4 \mathrm{mmHg}), \mathrm{P}<0.05 . \mathrm{PaO}_{2}$ was maintained during variable PEEP except in group 2 (318.5 \pm 82.9 at constant PEEP to $228.5 \pm 72.4$ at variable PEEP). There was a reduction in CO in group 3 after RM (3.9 \pm 1.1 before to $2.7 \pm 0.5 \mathrm{~L} \cdot \mathrm{min}^{-1} \cdot\left(\mathrm{m}^{2}\right)^{-1}$ after; $\left.\mathrm{P}<0.05\right)$, but there was not any difference between constant and variable $P E E P$ periods $\left(2.7 \pm 0.5\right.$ and $2.4 \pm 0.7 \mathrm{~L} \cdot \mathrm{min}^{-1} \cdot\left(\mathrm{m}^{2}\right)^{-1} ; \mathrm{P}>0.05$. Variable PEEP is able to maintain $\mathrm{PaO}_{2}$ when performed in combination with RM in dogs with ARDS. After RM, CO was reduced and there was no relevant difference between the variable and constant PEEP periods.
\end{abstract}

Key words: Acute respiratory distress syndrome (ARDS); PEEP; Mechanical ventilation; Oleic acid

\section{Introduction}

Acute respiratory distress syndrome (ARDS) is a severe lung disease caused by a variety of direct and indirect injuries. It is characterized by a decrease in pulmonary static compliance and arterial hypoxemia secondary to pulmonary edema and atelectasis (1). The use of mechanical ventilation to treat ARDS has been described since its definition in 1967 by Ashbaugh et al. (2). In the 1970's, high tidal volume and high pressures of mechanical ventilation were the rule to treat these patients, but in the 1980's ventilator-induced lung injury was described as a side effect of this form of mechanical ventilation (3-5).
Positive end-expiratory pressure (PEEP) has been used to avoid hypoxemia because it maintains lung end-expiratory inflation and prevent intratidal collapse and decollapse $(5,6)$. It is known that tidal over-distension caused by mechanical ventilation contributes to severe lung injury (4-6) and that gentle lung ventilation is the most efficient way to prevent hypoxemia and reduce lung injury $(7,8)$. Lung protection strategy generally requires the use of high PEEP to keep the alveoli open without cyclic distension, or the best PEEP to keep the oxygenation over $92 \%(8,9)$. But the use of high PEEP levels may result in severe complications such as

Correspondence: F.C. Lanza, Rua Estado de Israel, 465, apto. 23, 04022001 São Paulo, SP, Brasil.

E-mail: fernanda_lanza@hotmail.com

Received October 7, 2008. Accepted June 8, 2009 
volutrauma, barotrauma and mainly hemodynamic alterations, which can be associated with high tidal inflation or over-distention (1,10-12).

Therefore, the application of variable PEEP becomes an interesting alternative to the use of high levels of PEEP during mechanical ventilation because it recruits closed alveoli and avoids over-distention, and also hemodynamic complications. However, there are reports in the literature of lung injury induced by mechanical ventilator (10-13).

Variable PEEP consists of the application of PEEP alternating high and low pressure levels at the end of expiration (14-16). The use of variable PEEP in ARDS may assist pulmonary gas exchange $(16,17)$. The use of a lower PEEP should theoretically be associated with the prevention of hemodynamic alterations and pulmonary hyperinflation $(14,15)$. Sighs were later used in order to increase PEEP or tidal volume once or twice per minute during mechanical ventilation with the same objective in patients with lung injury, so as to restore oxygenation without complications of positive pressure (17).

The efficiency of recruitment maneuvers has been studied by several researchers, but for which length of time and how to carry out this procedure in patients with ARDS is controversial (18-23). We considered that if recruitment maneuvers maintain the lungs open avoiding recruitment and de-recruitment of the lung units, the associated use of variable PEEP should also yield better results.

The objective of the present study was to evaluate the effects of variable compared to constant (conventional) PEEP in dogs with ARDS induced by oleic acid, and to determine changes in gasometry and ventilatory mechanics (including hemodynamic alterations) at different pressure levels in the presence and absence of an alveolar recruitment maneuver.

\section{Material and Methods}

For the experiment, male mongrel dogs were anesthetized with sodium pentobarbital and paralysis was maintained by pancuronium bromide in iv boluses. The animals were submitted to orotracheal intubation using a number 8 Rush $^{\circledR}$ cannula (Germany) and placed under mechanical ventilation (Bird ${ }^{\circledR} 6400$ ventilator, Sti model, USA) in the supine position, with the following initial values: $100 \%$ $\mathrm{FiO}_{2}$, tidal volume of 6 to $8 \mathrm{~mL} / \mathrm{kg}$, respiratory rate of 25 to $35 \mathrm{bpm}$ to keep $\mathrm{PaCO}_{2}$ between 35 and $45 \mathrm{mmHg}$, and an inspiratory flow rate that would maintain the inspiratory/ expiratory ratio at 1:3. These settings were maintained during the entire experiment, with a PEEP of $5 \mathrm{cmH}_{2} \mathrm{O}$.

For arterial gasometry and measurement of mean arterial pressure (MAP) we used the femoral artery, while the femoral vein was used for hydration with $0.9 \%$ physiological saline (15 mL/kg during the procedures) and for oleic acid administration (an additional volume of $15 \mathrm{~mL}$ / $\mathrm{kg} 0.9 \%$ physiological saline was used after oleic acid administration). A Swan-Ganz catheter was inserted for hemodynamic measurements.

MAP had to be over $80 \mathrm{mmHg}$ at the beginning of the procedures in all groups.

\section{Protocol}

The study was approved by the Ethics Committee of the Federal University of São Paulo. After a stabilization period of 30 min using mechanical ventilation, the dogs were randomized into three groups of 6 animals each. Group 1, low variable PEEP; group 2, high variable PEEP; group 3, alveolar recruitment maneuver + high variable PEEP.

The study consisted of the following five experimental 30-min periods: i) Pre-lesion period. Introduction of catheters and mechanical ventilation using the initial parameters. During this period, dogs showing a $\mathrm{PaO}_{2}$ of over $400 \mathrm{mmHg}$ and an MAP over $80 \mathrm{mmHg}$ were included in the experiment; ii) Lesion period. ARDS was induced by the intravenous administration of $0.08 \mathrm{mg} / \mathrm{kg}$ body weight of oleic acid. ARDS was defined as a $\mathrm{PaO}_{2} / \mathrm{FiO}_{2}$ ratio lower than $150 \mathrm{mmHg}$. When this value was not obtained within $60 \mathrm{~min}$, the animal was excluded from the study. When the $\mathrm{pH}$ values fell below 7.25, sodium bicarbonate was administered; iii) Constant PEEP period 1 (PEEP 1). Constant PEEP was applied; iv) Variable PEEP period (PEEP). Variable PEEP was applied as described below; v) Constant PEEP period 2 (PEEP 2). Constant PEEP was applied (Figure 1).

\section{Variable PEEP}

During variable and constant PEEP periods, a specific PEEP value was established for each group: for group 1,

\begin{tabular}{|c|c|c|c|c|c|c|c|c|c|}
\hline & & & & Group 1 & $10 \mathrm{cmH}_{2} \mathrm{O}$ & $\rightarrow$ & $5-10 \mathrm{cmH}_{2} \mathrm{O}$ & $\rightarrow$ & $10 \mathrm{cmH}_{2} \mathrm{O}$ \\
\hline \multirow[t]{4}{*}{ Pre-lesion } & $\rightarrow$ & Lesion & $\rightarrow$ & Group 2 & $18 \mathrm{cmH}_{2} \mathrm{O}$ & $\rightarrow$ & $5-18 \mathrm{cmH}_{2} \mathrm{O}$ & $\rightarrow$ & $18 \mathrm{cmH}_{2} \mathrm{O}$ \\
\hline & & & & Group 3 & $\mathrm{RM}+18 \mathrm{cmH}_{2} \mathrm{O}$ & $\rightarrow$ & $5-18 \mathrm{cmH}_{2} \mathrm{O}$ & $\rightarrow$ & $18 \mathrm{cmH}_{2} \mathrm{O}$ \\
\hline & & & & & C PEEP 1 & $\rightarrow$ & V PEEP & $\rightarrow$ & C PEEP 2 \\
\hline & & & & & $30 \mathrm{~min}$ & & $30 \mathrm{~min}$ & & $30 \mathrm{~min}$ \\
\hline
\end{tabular}

Figure 1. Protocol of the 5 experimental 30 -min periods. PEEP = positive end-expiratory pressure; group 1 = low variable PEEP; group 2 = high variable PEEP; group 3 = alveolar recruitment maneuver $(\mathrm{RM})+$ high variable PEEP; C PEEP 1 = constant PEEP period $1 ; \mathrm{V}$ $\mathrm{PEEP}=$ variable PEEP; C PEEP 2 = constant PEEP period 2. 
PEEP was kept at $10 \mathrm{cmH}_{2} \mathrm{O}$ during constant periods and changed from 5 to $10 \mathrm{cmH}_{2} \mathrm{O}$ every $20 \mathrm{~s}$ during variable periods. For group 2, PEEP was kept at $18 \mathrm{cmH}_{2} \mathrm{O}$ during constant periods and increased from 5 to $18 \mathrm{cmH}_{2} \mathrm{O}$ every 20 s during variable periods. For group 3 , an alveolar recruitment maneuver was performed (elevation of PEEP up to a peak pressure of $50 \mathrm{cmH}_{2} \mathrm{O}$, repeated three times within one minute), followed by a constant period of PEEP, which was kept at $18 \mathrm{cmH}_{2} \mathrm{O}$; during variable periods, $\mathrm{PEEP}$ was changed from 5 to $18 \mathrm{cmH}_{2} \mathrm{O}$ every $20 \mathrm{~s}$.

\section{Measurements}

All measurements were made at the end of each 30-min experimental period: pre-lesion, lesion, constant PEEP 1, variable PEEP, and constant PEEP 2 periods. During the variable periods, measurements were made at 15 and 30 min to evaluate the changes. Mean values were used for statistical analysis. During variable PEEP periods, arterial blood samples, hemodynamic variables and respiratory mechanics were collected at a PEEP of $5 \mathrm{cmH}_{2} \mathrm{O}$.

Hemodynamic measurements. Cardiac output (CO) was measured by the thermodilution method using the Dixtal ${ }^{\circledR}$ model DX 2010 measuring system (Brazil, with a fluid temperature of 0 to $3^{\circ} \mathrm{C}$, and the mean of three measurements was recorded. Pulmonary capillary wedge pressure and pulmonary arterial pressure were also measured using a Swan-Ganz catheter. Mean systemic arterial pressure was monitored with the intravenous catheter in the femoral artery.

Respiratory measurements. Ventilatory levels: static compliance and plateau pressure were measured using a Ventcare-Takaoka ${ }^{\circledR}$ monitor (Brazil) and a pressure transducer. Inspiratory and expiratory flows were determined with a pneumotachograph installed between the $Y$ connection of the ventilator and the endotracheal tube. We performed one occlusion using the hold button of the mechanical ventilator for at least $3 \mathrm{~s}$ and maintained plateau pressure, tidal volume and PEEP, to calculate static compliance. To calculate static compliance during variable PEEP periods, this occlusion was performed when PEEP was $5 \mathrm{cmH}_{2} \mathrm{O}$. Arterial blood samples were collected from the femoral artery using a radiometer model ABL 330 (Uruguay) to measure
$\mathrm{pH}, \mathrm{PaO}_{2}, \mathrm{PaCO}_{2}, \mathrm{HCO}_{3}$, and base excess. Oxygen delivery to tissue $\left(\mathrm{DO}_{2}\right)$ was calculated with the equation: $\mathrm{DO}_{2}$ $=\mathrm{CaO}_{2} \mathrm{cc} / \mathrm{dL} \times(\mathrm{CO} \mathrm{L} / \mathrm{min}) \times 10$, where $\mathrm{CaO}_{2}$ is arterial oxygen content $=(\mathrm{Hb}) \times 1.38 \times \mathrm{SaO}_{2}+\left(0.003 \times \mathrm{PaO}_{2}\right), \mathrm{Hb}$ $=$ hemoglobin, $\mathrm{SaO}_{2}=$ arterial oxygen saturation, $\mathrm{PaO}_{2}=$ arterial oxygen pressure, $\mathrm{CO}=$ cardiac output, and 10 is the factor used to convert $\mathrm{L}$ to $\mathrm{dL}$.

The protocol time from the beginning of the procedure, and stabilization time until data collection was less than 4 $\mathrm{h}$ for each dog.

\section{Statistical analysis}

Data are reported as means \pm SD because they were found to have a normal distribution. Analysis consisted of five assessment periods within each group (dependent variables). Data were compared by analysis of variance for repeated measures (ANOVA) and complemented with the Tukey-Kramer test in case of statistical significance. In all analyses, statistical significance was accepted when $\mathrm{P}<0.05$.

\section{Results}

Eighteen dogs were studied, and no animal died or was excluded before the end of the experiment. Animal mean weight was $19.8 \pm 1.5 \mathrm{~kg}$. Table 1 shows the initial characteristics of all groups, that did not differ between groups.

Gas exchange. There was a statistically significant decrease in $\mathrm{PaO}_{2}$ after lung injury in all groups (Table 2). The introduction of PEEP-improved oxygenation was more evident when a higher PEEP was applied, i.e., in groups 2 and 3 , and a lower $\mathrm{PaO}_{2}$ were observed in group 1. In group $3, \mathrm{PaO}_{2}$ increased further due to the recruitment maneuver. $\mathrm{PaO}_{2}$ was not maintained during the variable PEEP period in group $2(\mathrm{P}=0.5261$; Table 2$)$. There was a significant increase in $\mathrm{PaCO}_{2}$ after lung injury during the constant PEEP 1 and PEEP 2 periods in all groups $(\mathrm{P}=$ 0.01 ; Table 2). $\mathrm{DO}_{2}$ was lower in group 3 compared with groups 1 and 2 after the lesion period $(P=0.001)$, but there was no difference between the constant and variable PEEP periods within any group ( $\mathrm{P}=0.6705$; Table 2$)$.

Ventilatory measurements. No improvement in static

Table 1. Initial characteristics of the animals studied.

\begin{tabular}{lccccc}
\hline & $\mathrm{RR}(\mathrm{rpm})$ & $\mathrm{Vt}(\mathrm{mL})$ & $\mathrm{PaO}_{2} / \mathrm{FiO}_{2}$ & $\mathrm{Cst}\left(\mathrm{cmH}_{2} \mathrm{O}\right)$ & $\mathrm{CO}\left(\mathrm{L} \cdot \mathrm{min}^{-1} \cdot\left(\mathrm{m}^{2}\right)^{-1}\right)$ \\
\hline Group 1 & $30.6 \pm 2.4$ & $126.6 \pm 41.7$ & $523.1 \pm 28.7$ & $28.4 \pm 7.1$ & $7.8 \pm 3.2$ \\
Group 2 & $29.4 \pm 1.9$ & $138.5 \pm 32.7$ & $533.1 \pm 18.5$ & $24.3 \pm 6.0$ & $6.8 \pm 2.9$ \\
Group 3 & $30.6 \pm 1.6$ & $120.0 \pm 20.0$ & $517.4 \pm 23.3$ & $21.8 \pm 4.2$ & $5.4 \pm 3.1$ \\
\hline
\end{tabular}

Data are reported as means \pm SD for 6 dogs in each group. $R R=$ respiratory rate; $r p m=$ respirations per minute; $\mathrm{Vt}=$ tidal volume; $\mathrm{PaO}_{2}=$ arterial oxygen pressure; $\mathrm{FiO}_{2}=$ inspiratory oxygen fraction; Cst = static compliance; $\mathrm{CO}$ $=$ cardiac output. See Figure 1 for explanation of groups. There were no statistical differences between groups $(P>$ 0.05, Tukey-Kramer test). 
Table 2. Gas exchange in groups studied in all phases of the protocol.

\begin{tabular}{|c|c|c|c|c|c|}
\hline & Pre-lesion & Lesion & Constant PEEP 1 & Variable PEEP & Constant PEEP 2 \\
\hline \multicolumn{6}{|l|}{ Group 1} \\
\hline $\mathrm{PaO}_{2}(\mathrm{mmHg})$ & $523.1 \pm 28.7$ & $69.8 \pm 16.4^{*}$ & $112.3 \pm 43.5^{\&}$ & $92.7 \pm 29.7$ & $105.9 \pm 42.4$ \\
\hline $\mathrm{PaCO}_{2}(\mathrm{mmHg})$ & $38.2 \pm 4.4$ & $40.5 \pm 6.6^{\#}$ & $48.2 \pm 2.0$ & $47.7 \pm 1.9$ & $50.6 \pm 5.2$ \\
\hline $\mathrm{DO}_{2}(\mathrm{~mL} \mathrm{O} / \mathrm{min})$ & $1480.7 \pm 173.2$ & $813.0 \pm 42.9^{*}$ & $876.7 \pm 65.7$ & $837.2 \pm 54.3$ & $822.5 \pm 46.2$ \\
\hline \multicolumn{6}{|l|}{ Group 2} \\
\hline $\mathrm{PaO}_{2}(\mathrm{mmHg})$ & $533.1 \pm 18.5$ & $72.3 \pm 14.8^{*}$ & $318.5 \pm 82.9^{\&}$ & $228.5 \pm 72.4^{\$}$ & $280.7 \pm 70.2$ \\
\hline $\mathrm{PaCO}_{2}(\mathrm{mmHg})$ & $38.2 \pm 4.4$ & $41.1 \pm 7.5^{\#}$ & $53.8 \pm 8.7$ & $49.7 \pm 9.9$ & $53.6 \pm 5.7$ \\
\hline $\mathrm{DO}_{2}(\mathrm{~mL} \mathrm{O} / \mathrm{min})$ & $1619.2 \pm 50.3$ & $849.3 \pm 41.5^{*}$ & $888.7 \pm 41.0$ & $797.4 \pm 60.7$ & $880.0 \pm 22.3$ \\
\hline \multicolumn{6}{|l|}{ Group 3} \\
\hline $\mathrm{PaO}_{2}(\mathrm{mmHg})$ & $517.4 \pm 23.3$ & $78.6 \pm 17.8^{*}$ & $395.9 \pm 41.5^{\&}$ & $356.2 \pm 65.4$ & $363.7 \pm 101.9$ \\
\hline $\mathrm{PaCO}_{2}(\mathrm{mmHg})$ & $38.2 \pm 4.1$ & $46.2 \pm 9.5^{\#}$ & $56.2 \pm 7.0$ & $47.6 \pm 6.2$ & $56.7 \pm 8.7$ \\
\hline $\mathrm{DO}_{2}(\mathrm{~mL} \mathrm{O} / \mathrm{min})$ & $1456.1 \pm 85.8$ & $719.1 \pm 92.3^{*}$ & $584.8 \pm 55.0$ & $524.2 \pm 50.4$ & $563.4 \pm 67.3$ \\
\hline
\end{tabular}

Data are reported as means $\pm S D$ for 6 dogs in each group. $\mathrm{PaO}_{2}=$ arterial oxygen pressure; $\mathrm{PaCO}_{2}=$ arterial carbon dioxide pressure; $\mathrm{DO}_{2}=$ oxygen delivery to tissues. See Figure 1 for explanation of groups. ${ }^{*} \mathrm{P}<0.001$ vs pre-lesion; ${ }^{\&} \mathrm{P}<0.05$ vs lesion; ${ }^{\$} \mathrm{P}<0.05$ vs constant PEEP 1; ${ }^{\mathrm{P}}<0.05$ vs constant PEEP 1 and constant PEEP 2 (TukeyKramer test).

Table 3. Effect of intermittent PEEP on respiratory and hemodynamic parameters of dogs with acute respiratory distress syndrome.

\begin{tabular}{lccccc}
\hline & Pre-lesion & Lesion & Constant PEEP 1 & Variable PEEP & Constant PEEP 2 \\
\hline Group 1 & & & & & \\
$\quad$ PPI $\left(\mathrm{cmH}_{2} \mathrm{O}\right)$ & $11.0 \pm 1.4$ & $15.3 \pm 2.4$ & $18.8 \pm 5.2^{+}$ & $14.3 \pm 4.4$ & $21.3 \pm 2.7^{+}$ \\
Cst $\left(\mathrm{mL} / \mathrm{cmH}_{2} \mathrm{O}\right)$ & $28.4 \pm 7.1$ & $17.0 \pm 5.8$ & $17.3 \pm 6.4$ & $17.6 \pm 6.9$ & $16.2 \pm 4.4$ \\
Group 2 & & & & \\
PPI $\left(\mathrm{cmH}_{2} \mathrm{O}\right)$ & $10.1 \pm 2.4$ & $15.6 \pm 2.2$ & $29.0 \pm 3.2^{+}$ & $16.0 \pm 3.2^{\#}$ & $28.8 \pm 3.5^{+}$ \\
Cst $\left(\mathrm{mL}^{-} \mathrm{cmH}_{2} \mathrm{O}\right)$ & $24.3 \pm 6.0$ & $17.0 \pm 5.2$ & $16.9 \pm 2.5$ & $17.0 \pm 6.8$ & $17.8 \pm 4.7$ \\
Group 3 & & & & \\
PPI $\left(\mathrm{cmH}_{2} \mathrm{O}\right)$ & $12.0 \pm 1.2$ & $17.5 \pm 1.5$ & $30.8 \pm 3.8^{+}$ & $17.6 \pm 1.9^{\#}$ & $30.5 \pm 2.5^{+}$ \\
Cst $\left(\mathrm{mL}^{\mathrm{cm}} \mathrm{cm}_{2} \mathrm{O}\right)$ & $21.8 \pm 4.2$ & $12.3 \pm 1.7$ & $13.4 \pm 3.9$ & $12.8 \pm 2.6$ & $13.2 \pm 2.4$ \\
\hline
\end{tabular}

Data are reported as means \pm SD for 6 dogs in each group. $P P I=$ plateau pressure; Cst $=$ static compliance. See Figure 1 for explanation of groups. ${ }^{+} \mathrm{P}<0.05$ vs pre-lesion; ${ }^{\#} \mathrm{P}<0.05$ vs constant PEEP 1 and constant PEEP 2 (Tukey-Kramer test).

compliance and no changes in plateau pressure $(\mathrm{P}=$ 0.2450 ) were observed in any of the groups during the constant or variable PEEP periods. There was a decrease in plateau pressure during variable PEEP in groups 2 and 3 ( $P=0.002$; Table 3).

Hemodynamic measurements. Significant hemodynamic repercussions were observed in group 3, with a significant decline in $\mathrm{CO}$ after the alveolar recruitment maneuver $(P=0.001)$, but there were no alterations between variable and constant PEEP $(P=0.2401$; Figure 2$)$. During the pre-lesion period, pulmonary capillary wedge pressure was below $12 \mathrm{mmHg}$ in all groups, and pulmonary arterial pressure was below $20 \mathrm{mmHg}$. There was no change in MAP $(P=0.5238)$. All dogs maintained an MAP of more than $70 \mathrm{mmHg}$ during the experiment (Figure 3).

\section{Discussion}

Analysis of dogs with ARDS induced by oleic acid administration showed that the use of variable PEEP is able to maintain $\mathrm{DO}_{2}$ when compared with constant PEEP, but $\mathrm{PaO}_{2}$ dropped when highly variable PEEP was used without 


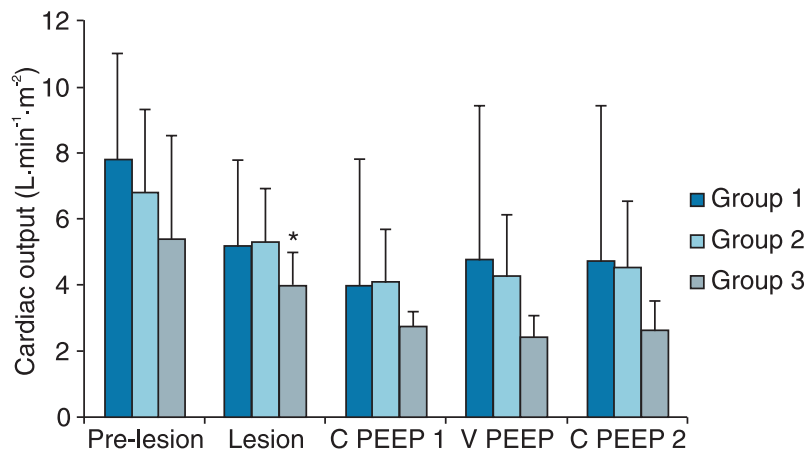

Figure 2. Cardiac output is reported as means \pm SD for all groups. See Figure 1 for explanation of abbreviations. ${ }^{*} P<0.05$ vs C PEEP 1, V PEEP and C PEEP 2 (Tukey-Kramer test).

recruitment maneuvers.

When the recruitment maneuver was applied in the present study, there was a $\mathrm{PaO}_{2}$ increase, which was sustained during variable PEEP in group 3. Thus, further collapsed areas were opened before we started the variation. The application of the recruitment maneuver $(23,24)$ has been standardized by Lachmann (19) according to "the open-lung concept". There is no doubt that initial lung recruitment rapidly improves oxygenation, which will only be maintained when using high PEEP levels (25-29). These observations were also made in ARDS patients with increased functional residual capacity and end-expiratory lung volume after the utilization of lung inflation or with sighs associated with PEEP $(16,30,31)$. It is known that low PEEP in ARDS patients cannot improve oxygenation $(1,6-9)$. This fact was also observed in our study in group 1 when $\mathrm{PaO}_{2}$ was kept lower than $150 \mathrm{mmHg}$ throughout the study.

Some studies have shown that a fluctuating PEEP in animals with lung injury is more effective for gas exchange than with constant PEEP $(14,16)$. Others have shown that the use of periodic PEEP can maintain adequate oxygenation in ARDS patients, but constant PEEP could improve these levels (17). In our study, we found an increase in $\mathrm{PaO}_{2}$ only in the group that underwent the recruitment maneuver, but in group 2 there was a decrease in $\mathrm{PaO}_{2}$. We did not change any other parameter (such as tidal volume or peak pressure) of mechanical ventilation as done in other studies (16,32-34). Except for PEEP during variable PEEP, this fact did not contribute to increased $\mathrm{PaO}_{2}$ in group 1 or to $\mathrm{PaO}_{2}$ maintenance in group 2 . In terms of oxygen delivery to tissue, we observed maintenance of $\mathrm{DO}_{2}$ in all groups during variable PEEP, but there were lower values in group 3 when compared to the other two groups, reflecting the decrease of $\mathrm{CO}$ after recruitment maneuvers. Despite the fact that $\mathrm{PaO}_{2}$ was the lowest in group 1 , the $\mathrm{DO}_{2}$ maintained normal values because there was no decrease in CO during variable PEEP.

Regarding alterations in $\mathrm{PaCO}_{2}$ caused by oleic acid-in-

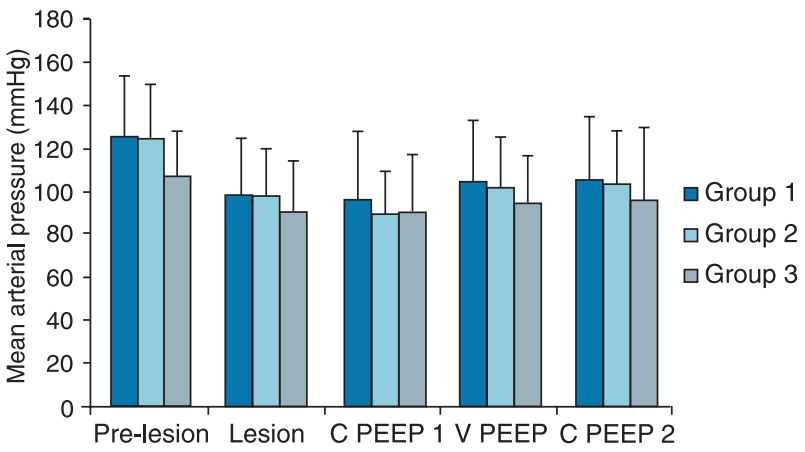

Figure 3. Mean arterial pressure is reported as means \pm SD for all groups. See Figure 1 for explanation of abbreviations. P > 0.05 (Tukey-Kramer test)

duced lung injury, we observed an elevation during constant PEEP periods, but not during variable PEEP periods. These findings can be explained by the changes in lung volume during oscillation of PEEP but have not been observed in other studies with variable PEEP $(16,17)$.

In patients with ARDS, the use of high PEEP might result in overdistension and higher inspiratory peak pressure because of a heterogeneous injury to the lung, which means that some areas can be overinflated whereas others are collapsed, resulting in a reduction in gas exchange and compliance. On the other hand, a decrease in PEEP may cause alveolar de-recruitment and lung injury caused by mechanical ventilation. However, as shown by Suh et al. (13), there is lung de-recruitment when lower PEEP is used, an event related to $\mathrm{PaO}_{2}$, indicating that, the lower the $\mathrm{PaO}_{2}$, the worse the de-recruitment $(1,4,6)$. In the present study, we did not perform histological analysis of the lung, but we observed the maintenance of $\mathrm{PaO}_{2}$ after recruitment maneuvers in group 3 , and therefore we believe that, lung de-recruitment occurred, it did not disturb the oxygenation.

As expected, we observed reduction in compliance after the lesion period, but we did not observe any difference in periodic or variable PEEP, possibly because complete expansion of the lungs was not used in this protocol.

We observed a change in hemodynamics only in group 3 , a fact possibly due to the higher intrapulmonary pressure used in this group. A fall in CO was observed after oleic acid-induced injury, as expected for the model used (25) and reduction of $\mathrm{CO}$ was also observed after the installation of PEEP; however, this decrease was only significant in group 3. Normally, hemodynamic repercussions in ARDS are influenced by the PEEP level applied (1). However, in the present study, despite a decline in $\mathrm{CO}$, no difference between the periods of variable and constant PEEP was observed in any group. We did not introduce vasoactive drugs because MAP was always over $70 \mathrm{mmHg}$ in all groups, but the animals received $0.9 \%$ physiological saline solution 
$(15 \mathrm{~mL} / \mathrm{kg})$ twice, i.e., during the procedure and after oleic acid administration. Even with numeric differences between phases in MAP there was not statistical difference probably because the standard deviation was high. Similar results were reported in a study of oleic acid-induced lung injury by Uchida et al. $(15,16)$. However, in a study of unilateral lung injury, Sato et al. (14) observed improved CO when fluctuating PEEP was used. Another explanation for the lack of changes in $\mathrm{CO}$ observed here is the fact that all measurements made during the variable PEEP period were performed at a pressure of $5 \mathrm{cmH}_{2} \mathrm{O}$.

The use of variable PEEP in our study was chosen because in previous tests in our laboratory we found that oscillation of PEEP of less than three times a minute, every $20 \mathrm{~s}$, made it difficult to maintain oxygenation, because positive end-expiratory pressure in ARDS is necessary for adequate oxygenation. The lower value of PEEP $\left(5 \mathrm{cmH}_{2} \mathrm{O}\right)$ was chosen because it is the lowest value regularly used during mechanical ventilation. PEEP of $18 \mathrm{cmH}_{2} \mathrm{O}$ was used because in previous pilot studies in our laboratory the second point of the pressure $x$ volume curve was around 16 in

\section{References}

1. Bernard GR, Artigas A, Brigham KL, Carlet J, Falke K, Hudson L, et al. The American-European Consensus Conference on ARDS. Definitions, mechanisms, relevant outcomes, and clinical trial coordination. Am J Respir Crit Care Med 1994; 149: 818-824.

2. Ashbaugh DG, Bigelow DB, Petty TL, Levine BE. Acute respiratory distress in adults. Lancet 1967; 2: 319-323.

3. Argiras EP, Blakeley CR, Dunnill MS, Otremski S, Sykes MK. High PEEP decreases hyaline membrane formation in surfactant deficient lungs. Br J Anaesth 1987; 59: 1278-1285.

4. Dreyfuss D, Soler P, Basset G, Saumon G. High inflation pressure pulmonary edema. Respective effects of high airway pressure, high tidal volume, and positive end-expiratory pressure. Am Rev Respir Dis 1988; 137: 1159-1164.

5. Muscedere JG, Mullen JB, Gan K, Slutsky AS. Tidal ventilation at low airway pressures can augment lung injury. $A m \mathrm{~J}$ Respir Crit Care Med 1994; 149: 1327-1334.

6. Gattinoni L, Pelosi P, Crotti S, Valenza F. Effects of positive end-expiratory pressure on regional distribution of tidal volume and recruitment in adult respiratory distress syndrome. Am J Respir Crit Care Med 1995; 151: 1807-1814.

7. Hickling KG, Henderson SJ, Jackson R. Low mortality associated with low volume pressure limited ventilation with permissive hypercapnia in severe adult respiratory distress syndrome. Intensive Care Med 1990; 16: 372-377.

8. Amato MB, Barbas CS, Medeiros DM, Magaldi RB, Schettino GP, Lorenzi-Filho G, et al. Effect of a protective-ventilation strategy on mortality in the acute respiratory distress syndrome. N Engl J Med 1998; 338: 347-354.

9. Ventilation with lower tidal volumes as compared with traditional tidal volumes for acute lung injury and the acute respiratory distress syndrome. The Acute Respiratory Distress Syndrome Network. N Engl J Med 2000; 342: 1301-1308.

10. Pierson DJ. Complications associated with mechanical dogs with ARDS. Thus, we decided to increase $2 \mathrm{cmH}_{2} \mathrm{O}$ to use PEEP value between the first and the second inflexion point in pressure $x$ volume curve. And finally, the PEEP of $10 \mathrm{cmH}_{2} \mathrm{O}$ was chosen arbitrarily because it was close to the other two values.

In the present study, PEEP was changed to a period of 30 min and therefore we do not know whether a longer period or different intervals would be able to maintain oxygenation or would lead to hemodynamic alterations, since some studies have demonstrated that the beneficial effects of recruitment may only be maintained for short periods of time $(20,21)$. We chose on this period because we believe it is sufficient to evaluate variations in the respiratory system. We did not study a variable PEEP of $10 \mathrm{cmH}_{2} \mathrm{O}$ in combination with a recruitment maneuver since previous experience from our laboratory demonstrated that this PEEP level is unable to maintain the oxygenation gain obtained with previous alveolar recruitment. Different types of variable PEEP in terms of the number of elevations per minute and pressure values might alter the results.

ventilation. Crit Care Clin 1990; 6: 711-724.

11. Stewart TE, Meade MO, Cook DJ, Granton JT, Hodder RV, Lapinsky SE, et al. Evaluation of a ventilation strategy to prevent barotrauma in patients at high risk for acute respiratory distress syndrome. Pressure- and Volume-Limited Ventilation Strategy Group. N Engl J Med 1998; 338: 355-361.

12. Pelosi P, D’Andrea L, Vitale G, Pesenti A, Gattinoni L. Vertical gradient of regional lung inflation in adult respiratory distress syndrome. Am J Respir Crit Care Med 1994; 149: 8-13.

13. Suh GY, Koh Y, Chung MP, An $\mathrm{CH}$, Kim H, Jang WY, et al. Repeated derecruitments accentuate lung injury during mechanical ventilation. Crit Care Med 2002; 30: 1848-1853.

14. Sato J, Inaba H, Uchida H, Sakurada M, Ohwada T, Mizuguchi T. Comparison between fluctuating PEEP and conventional PEEP in dogs with lung injury induced by blood aspiration. Acta Anaesthesiol Scand 1988; 32: 369-373.

15. Inaba H, Sato J, Uchida H, Sakurada M, Ohwada T, Mizuguchi T. Fluctuating PEEP (F-PEEP) versus conventional $\mathrm{PEEP}$ in dogs with asymmetrical lung injury. Acta Anaesthesiol Scand 1988; 32: 374-378.

16. Uchida H, Inaba H, Sato J, Sakurada M, Mizuguchi T. Fluctuating PEEP versus conventional PEEP in diffuse and unilateral lung injury induced by oleic acid. Acta Anaesthesiol Scand 1988; 32: 420-425.

17. Foti G, Cereda M, Sparacino ME, De Marchi L, Villa F, Pesenti A. Effects of periodic lung recruitment maneuvers on gas exchange and respiratory mechanics in mechanically ventilated acute respiratory distress syndrome (ARDS) patients. Intensive Care Med 2000; 26: 501-507.

18. Pelosi P, Cadringher P, Bottino N, Panigada M, Carrieri F, Riva E, et al. Sigh in acute respiratory distress syndrome. Am J Respir Crit Care Med 1999; 159: 872-880.

19. Lachmann B. Open up the lung and keep the lung open. 
Intensive Care Med 1992; 18: 319-321.

20. Tusman G, Bohm SH, Vazquez de Anda GF, do Campo JL, Lachmann B. Alveolar recruitment strategy' improves arterial oxygenation during general anaesthesia. Br J Anaesth 1999; 82: 8-13.

21. Lapinsky SE, Aubin M, Mehta S, Boiteau P, Slutsky AS. Safety and efficacy of a sustained inflation for alveolar recruitment in adults with respiratory failure. Intensive Care Med 1999; 25: 1297-1301.

22. Kacmarek RM, Kallet RH. Respiratory controversies in the critical care setting. Should recruitment maneuvers be used in the management of ALI and ARDS? Respir Care 2007; 52: 622-631.

23. Hansen LK, Koefoed-Nielsen J, Nielsen J, Larsson A. Are selective lung recruitment maneuvers hemodynamically safe in severe hypovolemia? An experimental study in hypovolemic pigs with lobar collapse. Anesth Analg 2007; 105: 729-734.

24. Kloot TE, Blanch L, Melynne YA, Weinert C, Adams AB, Marini JJ, et al. Recruitment maneuvers in three experimental models of acute lung injury. Effect on lung volume and gas exchange. Am J Respir Crit Care Med 2000; 161: 1485-1494.

25. Suter PM. Let us recruit the lung and keep an open mind. Intensive Care Med 2000; 26: 491-492.

26. Hodgson C, Keating JL, Holland AE, Davies AR, Smirneos L, Bradley SJ, et al. Recruitment manoeuvres for adults with acute lung injury receiving mechanical ventilation. Cochrane Database Syst Rev 2009; CD006667.

27. Villagra A, Ochagavia A, Vatua S, Murias G, del Mar FM, Lopez AJ, et al. Recruitment maneuvers during lung protec- tive ventilation in acute respiratory distress syndrome. $\mathrm{Am} \mathrm{J}$ Respir Crit Care Med 2002; 165: 165-170.

28. Grasso S, Mascia L, Del Turco M, Malacarne P, Giunta F, Brochard L, et al. Effects of recruiting maneuvers in patients with acute respiratory distress syndrome ventilated with protective ventilatory strategy. Anesthesiology 2002; 96: 795-802.

29. Halter JM, Steinberg JM, Schiller HJ, DaSilva M, Gatto LA, Landas $\mathrm{S}$, et al. Positive end-expiratory pressure after a recruitment maneuver prevents both alveolar collapse and recruitment/derecruitment. Am J Respir Crit Care Med 2003; 167: 1620-1626.

30. Patroniti N, Foti G, Cortinovis B, Maggioni E, Bigatello LM, Cereda $\mathrm{M}$, et al. Sigh improves gas exchange and lung volume in patients with acute respiratory distress syndrome undergoing pressure support ventilation. Anesthesiology 2002; 96: 788-794.

31. Pelosi P, Bottino N, Chiumello D, Caironi P, Panigada M, Gamberoni $\mathrm{C}$, et al. Sigh in supine and prone position during acute respiratory distress syndrome. Am J Respir Crit Care Med 2003; 167: 521-527.

32. Huh JW, Jung H, Choi HS, Hong SB, Lim CM, Koh Y. Efficacy of positive end-expiratory pressure titration after the alveolar recruitment manoeuvre in patients with acute respiratory distress syndrome. Crit Care 2009; 13: R22.

33. Housley E, Louzada N, Becklake MR. To sigh or not to sigh. Am Rev Respir Dis 1970; 101: 611-614.

34. Antonaglia V, Pascotto S, Simoni LD, Zin WA. Effects of a sigh on the respiratory mechanical properties in ALI patients. J Clin Monit Comput 2006; 20: 243-249. 